\title{
Real-Time Mobile-Phone-Aided Melanoma Skin Lesion Detection Using Triangulation Technique
}

\author{
Kumud Tiwari, Amity University, Lucknow, India \\ Sachin Kumar, Amity University, Lucknow, India \\ R. K. Tiwari, Department of Physics and Electronics, Dr. RML Avadh University, Faizabad, India
}

\begin{abstract}
Melanoma is a harmful disease among all types of skin cancer. Genetic factors and the exposure of UV rays causes melanoma skin lesions. Early diagnosis is important to identify malignant melanomas to improve the patient prognosis. A biopsy is a traditional method which is painful and invasive when used for skin cancer detection. This method requires laboratory testing which is not very efficient and time-consuming to detect skin lesions. To solve the above issue, a computer aided diagnosis (CAD) for skin lesion detection is needed. In this article, we have developed a mobile application with the capabilities to segment skin lesions in dermoscopy images using a triangulation method and categorize them into malignant or bengin lesions through a supervised method which is convolution neural network $(\mathrm{CNN})$. This mobile application will make the skin cancer detection non-invasive which does not require any laboratory testing, making the detection less time consuming and inexpensive with a detection accuracy of $81 \%$.
\end{abstract}

\section{KEYWORDS}

Automatic segmentation, Computer aided diagnosis, Convolution Neural network, Mobile application, Skin lesion

\section{INTRODUCTION}

Skin forms the first layer of defense mechanism against diseases and infections, primarily at primaface protection from UV radiation is ensured by skin. If proper care is not taken after some year the skin itself can turn into a source of a diseases. Most dangerous kind of skin disease is skin cancer and melanoma is one of them which accounts for almost $4 \%$ of all skin cancer. If melanoma is not identified at early stages, it can grow deeper into the skin and may spread across other parts of the body which is dangerous as it is very difficult to cure (Bafounta, Beauchet, Aegerter, \& Saiag, 2001). Figure 1 shows images of skin lesions.

The diagnosis accuracy of melanoma stays between $75 \%$ to $84 \%$ even after being examined by the expert dermatologists. For increasing speed and diagnosis accuracy the computer aided diagnostics is required (Argenziano et al., 2003; Garnavi, Aldeen, \& Bailey, 2012). Some information can be extracted using computers, like asymmetry, texture features, color variation, which can not be readily perceived using human eyes. Currently most used methods for classification of skin lesion rely on hand-crafted features like ABCDE rule (Nachbar, Stolz, Merkle, \& Cognetta, 1994), Menzies method (Menzies, 2001), 3-point checklist (Soyer et al., 2004), CASH (Henning et al., 2007) and 7-point checklist (Argenziano et al., 2011). Personal experience is what the physicians depends on evaluating

This article, originally published under IGI Global's copyright on July 1, 2020 will proceed with publication as an Open Access article starting on January 25, 2021 in the gold Open Access journal, International Journal of E-Health and Medical Communications (converted to gold Open Access January 1, 2021), and will be distributed under the terms of the Creative Commons Attribution License (http://creativecommons.org/licenses/by/4.0/) which permits unrestricted use, distribution, and production in any medium, provided the author of the original work and original publication source are properly credited. 

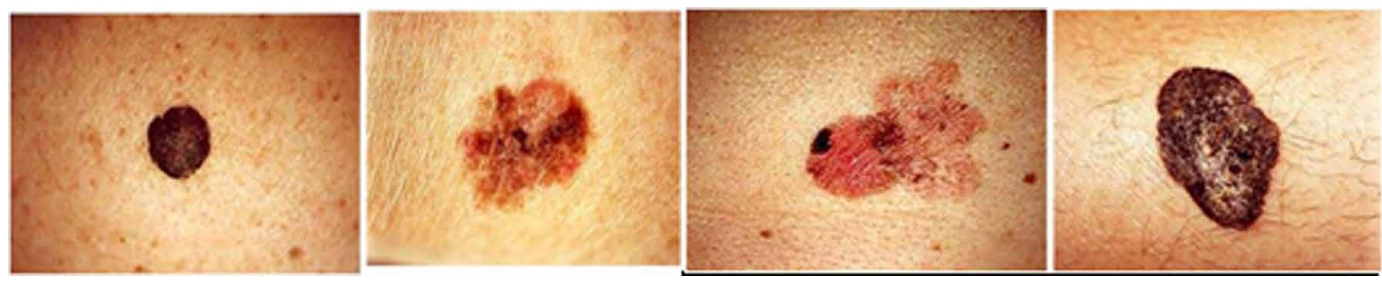

each patient's lesions over case-by-case basis by captivating into patterns of patient's local lesion in contrast to that of the whole body (Gachon et al., 2005). Without any type of computer-based assistance, the accuracy of clinical diagnosis for melanoma lesion detection is reported to be arround $65 \%$ to $80 \%$ (Argenziano \& Soyer, 2001). Use of dermoscopic images, pictures taken skin by a skin surface microscopy (Kittler, Pehamberger, Wolff, \& Binder, 2002), can increase diagnostic accuracy of the skin lesions by arround 49\% (Kawahara, BenTaieb, \& Hamarneh, 2016). In Figure 1, it can be visually seen the differences between melanoma and benign skin lesions, making it very difficult to distinguish between the two cases, even for trained medical experts. For the reasons described above, the physician should be provided with an intelligent medical imaging-based skin lesion diagnosis system that can assist a physician in classifying skin lesions. The Menzies, ABCD Rule and Seven Point Checklist are one of the few most referred algorithms which may improve the Melanoma diagnostics in Skin Cancer (Kawahara, BenTaieb, \& Hamarneh, 2016). A computer image based melanoma diagnosis follows a sequence which contains the following steps: 1. Scanning the image of skin lesion, 2. Skin Lesion segmentation, 3. Extraction of Lesion's features, 4. Segmentation of Skin Lesion and 5. Feature classification (Celebi, Iyatomi, Schaefer, \& Stoeck, 2009).

This research article is divided into seven sections; Section II gives an explaination of different types of skin lesion. Section III presents the different melanoma diagnosis techniques. Section IV describes the work that has been done related to skin lesion image recognition and detection. In section V, a generalized model for improved detection and prediction of skin lesion is presented. In Section VI, The mobile implementation of the dermoscopy image analysis is presented which helps to detect the skin lesion. In Section VII, we have shown the results and in Section VIII conclusion of paper is discussed.

\section{TYPE OF SKIN LESION}

First step of any dermoscopic examination is to distinguish between non-melanocytic and melanocytic lesions as given in Figure 2. These two classes differ since melanocytic lesions arise from a proliferation of melanocytes which produce a pigment called melanin. Both classes include malignant and benign lesions. Neverthless, as melanoma which belongs to melanocytic class is considered the most problematic lesion, it becomes a crucial to differentiate between this type of lesion and the remaining. There are four forms of non-melanocytic lesion known by seborrheic keratosis, vascular lesions, basal cell carcinoma and dermatofibroma which are characterized by specific morphological features. The most incident malignant neoplasm in humans is basal cell carcinoma. Nonetheless, as its growth is slow, they are treated as harmless lesions. However, if appropriate treatment is not carried out, they can produce numerous structural destruction in tissues leading to death. The other three lesions are benign from which dermatofibroma occurs with more regularly, in different portions of the body, mainly extremities. Figure 2 shows examples of Non Melanocytic and Melanocytic lesions.

On the other hand, melanocytic lesions are also distinguished between the malignant and benign ones. The coloration that often characterizes a malignant melanoma includes black and brown, but regions of blue, red or white can also appear. The concept of melanoma in situ mentions to a phase 
Figure 2. Non-Melanocytic and Melanocytic lesions-example: (1) Benign; (2)Solar; (3) Melanocytic Nevus; (4) Atypical Nevus are samples of melanocytic lesions; (5) Seborrhoeic Keratosis; (6) Basal cell carcinoma, (7) Dermatofibroma; (8) Vascular lesions; (9) Malonama are examples of non-melanocytic lesions
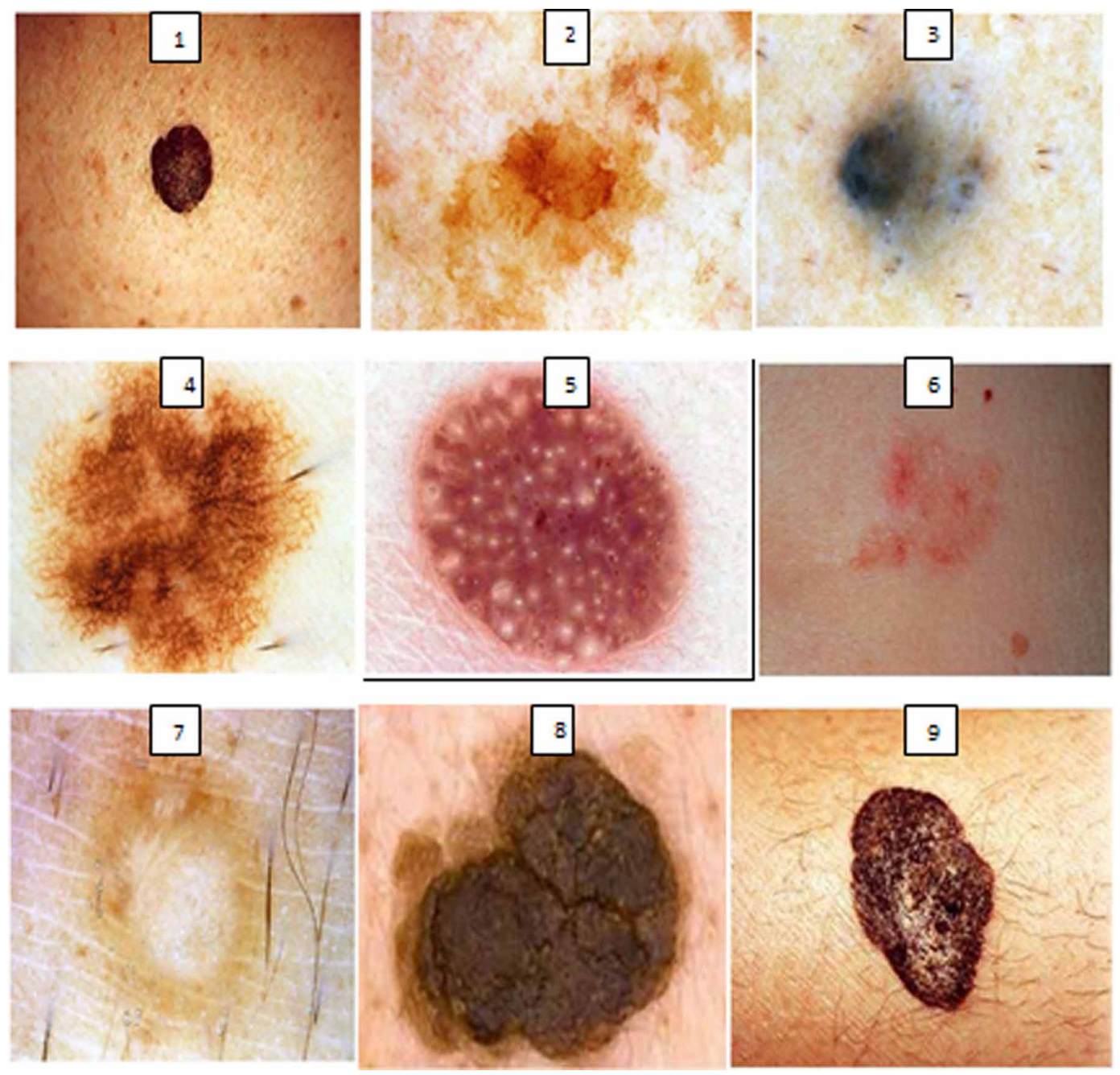

of neoplasm which is present on epidermis. As it is not in skin dermis, there is no continuity with vascular plexus and it does not have a potential for metastasis. Nevi are benign melanocytic lesions which are classified as congenital when present at birth or acquired when genetic changes are not their cause. Estimates suggest that about $50 \%$ of melanomas arise from pre-existing melanocytic nevi. One of the most important types is Clark nevu as it is considered a relevant precursor of melanoma. It is also called dysplastic or atypical nevi as its appearance is different from the regular ones. Generally, it is large and has irregular borders. Furthermore, the color of it is not uniform, ranging from pink color to dark brown color. One of the major challenges in dermoscopy is the distinction between melanomas and other melanocytic lesions. Sometimes, the detection of malignant neoplasms by dermatologists is tough due to the similarities that many melanomas share with nevi. This fact constitutes a motivation to develop CAD systems to allow a more efficent detection of these diseases. 


\section{MELANOMA DIAGNOSIS TECHNIQUES}

Melanoma is caused by cancerous cell growth due to damaged skin cells whose multiplication creates malignant tumors. The aforementioned cells come from melanocytes. In the epidermis, melanocytes are initiated, which is top cover of the skin and are responsible for production of melanin, a pigment meant to protect the skin from the negative impact of sun radiation. The most common procedure for melanoma diagnosis begins with a physical examination by a doctor, followed by a non-invasive diagnostic technique known as dermoscopy. Dermoscopy entails the magnified visualization of the pigmented lesion with a device that allows digital imaging, such as a camera or a dermatoscope. Some of the melanoma diagnosis techniques(see Table 1) are:

1. ABCD-E Rule: Dermatologists first used, ABCD rule for the detection of lesion to assess the threat of malignity of pigmented lesion (Stolz, 1994). It takes into consideration parameters present in the lesion: asymmetrical shape, irregular border, diameter and unevenness of its color. This rule has been further completed with the inclusion of the evolution factor (ABCDE rule).

(A) stands for ASYMMETRY: For the measurement of the asymmetry score of the lesion, lesion is separate into minor axis and major axis. Asymmetry is evaluated for both axis regarding colors, shape or dermoscopic structures. 2 score is given if there is asymmetry along both the axis(i.e major and minor), it is scored 1 if there is asymmetry along one axis, and 0 otherwise.

(B) stands for BORDER: Edges can be irregular, notched, ragged or blurred. For the calculation of the border, lesion is divided into eight sections and the score of 1 is given to a sharp pattern, 8 score will be given to the maximum irregular border and 0 score will be given to the minimum irregular border.

(C) stands for COLOR: The skin lesion color is generally not all over the same, but may have diverse shades of black or brown, occasionally with patches of white, blue or red. For the diagnoses of melanoma, the score is increased by one for each prevailing color (red, dark brown, light brown, white, blue-grey and black). If we have all the colors the score is 6 and 0 for the minimum.

(D) stands for DIAMETER: Depending upon the scales, we can find the exact diameter of the skin lesion $\&$ if the diameter is found to be greater than $6 \mathrm{~mm}$ then most likely they are malignant melanoma..

At the end, the TDS can give us a score base on all four parameters, which based on that we make a decision. If the score is less than 4.75 , then we can say it's a benign skin lesion, for TDS between 4.75 and 5.45,we are suspicious to melanoma and if the TDS is greater than 5.45, we are greatly suspicious to melanoma.

To calculate final score:

Total Dermoscopy Score $(T D S)=1.3 \times A+0.1 \times B+0.5 \times c+0.5 \times D$

(E) stands for Evolution: check the evolution and changing of the mole in size, shape and color during the time.

2. Pattern Analysis: This algorithms always tries to identify the specific patterns present in skin lesion, which may be local (streaks, blotches, pigmented network, hypopigmentation, blue-whitish veil, regression structures, vascular structures, dots/globules/moles) or global (globular,reticular, cobblestone, parallel, starburst, homogeneous, nonspecific, multicomponent)

3. The 3-Point Checklist: This method is used to detect skin lesion using features like: asymmetry, blue-white structure and atypical pigment network.

4. Texture Analysis: To analyse and categorize texture features as "Fine", "Irregular" or "Rough."

5. The Menzies method: The Menzies scale is used to analysis the skin lesion, it offers a binary classification based on negative (axial asymmetry, color symmetry, presence of one color) and 
positive features (discoloration, many colors, blue-white veil, certain patterns). Melanoma will be diagnosed if we don't have any of these feature sets like a negative sign or at least one of the positive sign. The absence of negative feature paired with any positive feature implies the presence of melanoma (Menzies, 2001).

6. The 7-Point Checklist: A score based diagnostic method which assigns quantitative scores to a small set of identifiable features which includes irregular dots/globules, regression structures, irregular blotches, irregular streaks, atypical vascular pattern, atypical pigment network and blue-whitish veil (Argenziano et al., 2011). Table 1 shows diagnoses of skin cancer.

Table 1. Diagnosis of skin cancer

\begin{tabular}{|c|c|c|c|c|}
\hline Approaches & Features & Weight & Score Range & $\begin{array}{c}\text { Creteria of } \\
\text { Classification }\end{array}$ \\
\hline \multirow{4}{*}{$\begin{array}{l}\text { ABCD rule of } \\
\text { demosopy }\end{array}$} & Asymmetry & 1.3 & 0 to 2 & \multirow{4}{*}{$\begin{array}{l}<4.75=\text { Benign } \\
\text { melanocytic Lesion; } \\
4.8-5.45=\text { Suspicious } \\
\text { lesion; } \\
>5 . .45=\text { Lesion } \\
\text { greatly suspicious to } \\
\text { melanoma }\end{array}$} \\
\hline & Border irregularity & 0.1 & 0 to 8 & \\
\hline & Color & 0.5 & 0 to 6 & \\
\hline & $\begin{array}{l}\text { Dermoscopic } \\
\text { Structure }\end{array}$ & 0.5 & 0 to 5 & \\
\hline \multirow{7}{*}{ 7-point checklist } & $\begin{array}{l}\text { Irregular dots and } \\
\text { globules }\end{array}$ & 1 & 0 or 1 & \multirow{7}{*}{$>=3=$ melanoma } \\
\hline & Regression pattern & 1 & 0 or 1 & \\
\hline & Blotches & 1 & 0 or 1 & \\
\hline & Straks & 1 & 0 or 1 & \\
\hline & $\begin{array}{l}\text { Atypical vascular } \\
\text { pattern }\end{array}$ & 2 & 0 or 1 & \\
\hline & $\begin{array}{l}\text { Atypical pigment } \\
\text { network }\end{array}$ & 2 & 0 or 1 & \\
\hline & Gray- blue areas & 2 & 0 or 1 & \\
\hline
\end{tabular}

\section{LITERATURE REVIEW}

Skin cancer cases are increasing rapidly, with annual growth of three to seven percent. It is predicted that by the year 2030 more than 12 million people will be affected from this disease (Iyatomi et al., 2006). Early detection is the most effective tool for controlling this kind of cancer. The use of ABCD rule is to differentiate between benign and malignant skin lesion. This method evaluates the colour, asymmetry, edge and size of the skin lesion for the generation of a diagnostic report (Satheesha, Narayana, \& Giriprasad, 2012). The measurement of geometric characteristics has led the scientific community to propose Computer-Aided Diagnosis Systems (CADS) for early detection of skin cancer (Korotkov \& Garcia, 2012). Fundamentally, any CADS is composed of four blocks: image processing, edge detection and segmentation, classification and feature extraction. The step of extracting the geometric characteristics and colour of the lesion are the basic requirement for accurate diagnosis of skin lesion. Several proposals have been used for measuring asymmetry and edge features. These proposals can be clustered into three groups: signal processing based methods, fractal approaches and measurement of the region using geometric properties, the first two methods are least effective 
to describe the properties of asymmetry and border (Maglogiannis \& Doukas, 2009). Most of the CAD systems used for evaluation and diagnosis of the skin lesion are highly expensive. In various research papers, the skin lesion segmentation was based on shape, color, texture and luminance. Some of the border detection method includes global thresholding, histogram thresholding and hybrid thresholding (Liu, Sun, Smith, Smith, \& Warr, 2012). In this paper, the author used the Euclidean Distance Tranformation technique by dividing the imput image into different clinically significant regions based on color and texture features (Ng, Fung, \& Lee, 2005). The author applied an automated global border-detection method (A high performance technique to detect the border of melanoma lesions) based on global histogram thresholding and color space analysis (Garnavi et al., 2010). In a few papers, the symmetry feature is evaluated on behalf of geometrical measurement of the skin lesion such as: circularity index, symmetric distance etc. The proposed system was introduced for automatic extraction of lesion area and to classify them as benign or malignant (Celebi et al., 2007) the study starts with the process of de-noising and removing the unwanted parts such as hair, prior to the segmentation of the lesion. It was tested with 141 different images of 5 classes of the diseases used for classification of extracted features (Maglogiannis \& Doukas, 2009). The selected features are applied to a SVM for the classification of melanomas as malignant or benign (Sumithra, Suhil, \& Guru, 2015; Razmjooy, Mousavi, Soleymani, \& Khotbesara, 2013). New study based on texture analysis, the origin image is resized to a fixed scale before it converts from RGB to a grey scale image. Then the co-occurrence matrix is mapped on the converted gray scale image to excerpt important features. The extracted features are based on combination between multilayer perceptron classifier and gray level co-occurrence matrix to classify between non-melanoma and malignant melanoma (Sheha, Mabrouk, \& Sharawy, 2012). Table 2 reviews skin image recognition on smart phones.

\section{METHODOLOGY FOR DERMOSCOPY IMAGE ANALYSIS}

Main focus of this study is to create a real-time mobile-based application which can detect skin cancer. Using the application, a mobile phone could be used as a detecting tool to analyse skin lesions in a person and it will evaluate the image and notify the user about type of lesion. Figure 3 shows the proposed dermoscopy image analysis system.

Extracting the contour of the lesion area is done from the proposed algorithm and it is organised in two stages: Edge Detection and Triangulation method (see Figure 4). Edge detector is used to find the edges of lesion and Triangulation method is used for tracing the shape of skin lesion.

Step 1: To determine the center of lesion(see Figure 5), first the dermoscopic image is transformed into gray-scaled image using equation: $I=0.2989 \times R+0.5870 \times G+0.1140 \times B$. Later, normalization of I between 0 and 1 take place and darker pixels with $I \leq I_{d}$ are taken out.

Resulting, $\mathrm{X}$ and $\mathrm{Y}$ which are coordinates of darker pixels and are writtenas as:

$$
\begin{aligned}
&(X, Y)=\left\{(x, y) \mid I_{x, y} \leq I_{d}\right\} . \\
& x_{c}=\frac{1}{N} \times \sum_{i=1}^{N} x_{i} \text { and } y_{c}=\frac{1}{N} \times \sum_{i=1}^{N} y_{i} .
\end{aligned}
$$

Where $\mathrm{N}=|\mathrm{X}|=|\mathrm{Y}|$. Simply $\left(x_{c}, y_{c}\right)$ as centroid of dark pixels.

$D_{x, y}$ is radial distance, calculated for each pixel in the image by computing the euclidean distance between pixels and the extracted center.

$$
D_{x, y}=\sqrt{\left(x-x_{c}\right)^{2}+\left(y-y_{c}\right)^{2}}
$$


Table 2. Review of skin image recognition on a smartphone

\begin{tabular}{|l|l|}
\hline \multicolumn{1}{|c|}{ AUTHOR } & \multicolumn{1}{c|}{ INVESTIGATION } \\
\hline $\begin{array}{l}\text { (Massone, Brunasso, } \\
\text { Campbell, \& Soyer, 2009) }\end{array}$ & $\begin{array}{l}\text { Proposed study introduces mobile teledermoscopy by one click for the diagnosis of } \\
\text { melanoma. System lacked module for automatic image processing and is dependent totally } \\
\text { on the dermatologist, availability to diagnose and classify the dermoscopic images. Thus, } \\
\text { it is not regarded as a real-time system. }\end{array}$ \\
\hline $\begin{array}{l}\text { Lancaster, Yuan, \& } \\
\text { Zouridakis, 2011) }\end{array}$ & $\begin{array}{l}\text { Proposed model works on a portable library on handheld devices for melanoma detection. } \\
\text { The author used most of the time in consuming and computational intensive algorithms of } \\
\text { library for segmentation of the images and there classification. The system do not allow } \\
\text { the user to use smart phone to capture image. }\end{array}$ \\
\hline $\begin{array}{l}\text { (Ramlakhan \& Shang, } \\
\text { 2011) }\end{array}$ & $\begin{array}{l}\text { Proposed study works for the classification of skin lesion on mobile automated system. } \\
\text { The system consist of three main components that is image segmentation, feature } \\
\text { estimation, and classification. The system accomplish an average accuracy of } 66.7 \%, \\
\text { specificity of 80.5\% and sensitivity of 60.7\% as shown by experimental result which was } \\
\text { not highly efficient. }\end{array}$ \\
\hline $\begin{array}{l}\text { (Karargyris, Karargyris, \& } \\
\text { Pantelopoulos, 2012) }\end{array}$ & $\begin{array}{l}\text { Proposed model works on monitoring skin cancer using advanced image-processing } \\
\text { mobile application. The author developed an application for prevention of skin disease } \\
\text { using a mobile device with a very small database consisting of only 6 images for benign } \\
\text { cases and 6 images for doubtful cases. }\end{array}$ \\
\hline $\begin{array}{l}\text { (Doukas, Stagkopoulos, } \\
\text { Kiranoudis, \& } \\
\text { Maglogiannis, 2012) }\end{array}$ & $\begin{array}{l}\text { The proposed study works on mobile application which is under development that could } \\
\text { obtain moles and recognize them in an image and classify it into benign, nevus and } \\
\text { melanoma lesions. 77.06\% is classification accuracy of support vector machine. }\end{array}$ \\
\hline
\end{tabular}

Figure 3. Skin lesion detection proposed model

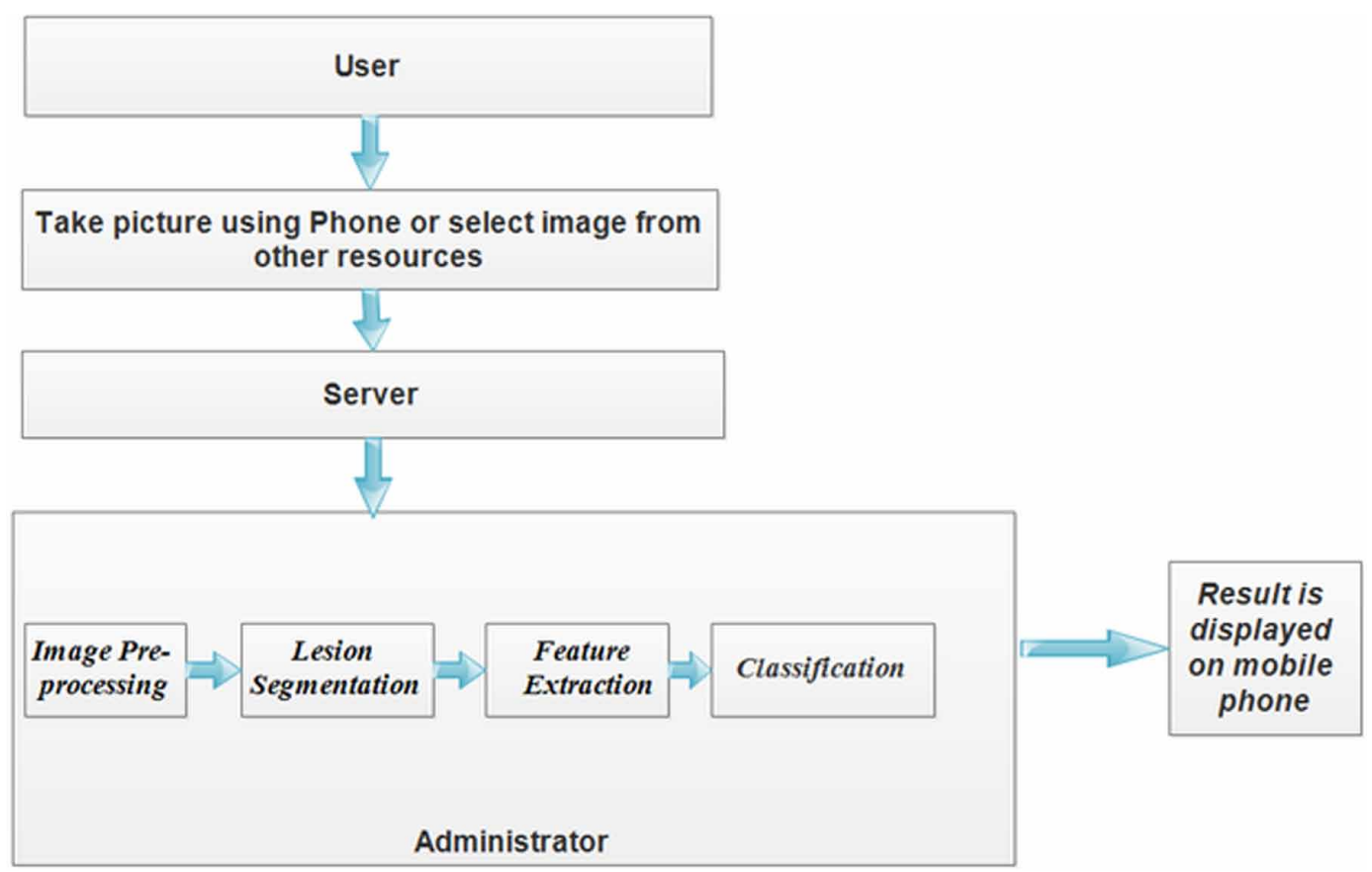




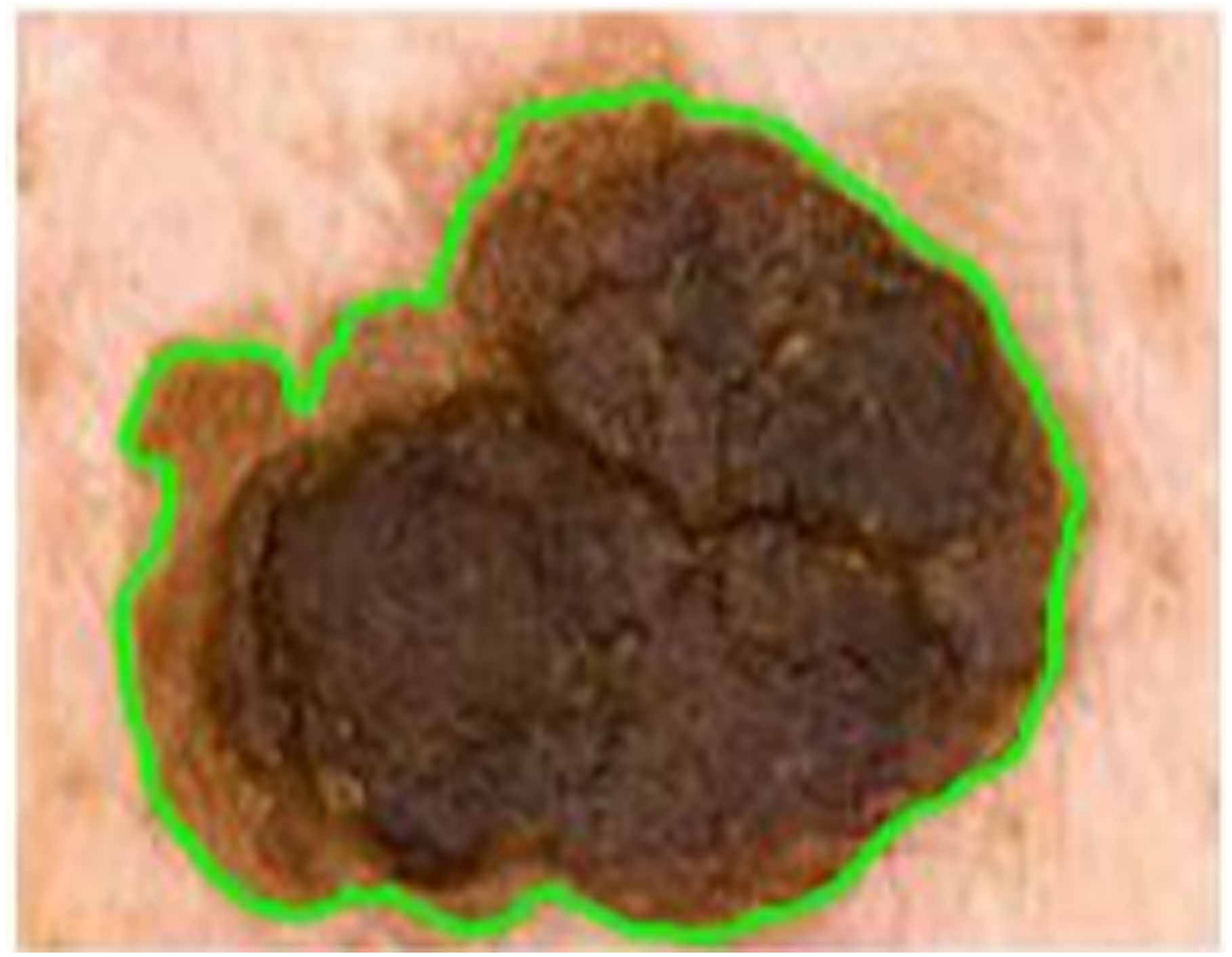

Step 2: After determing center of skin lesion, the lesion is first divided into $\mathrm{N}$ partitions and edge point are joined to form triangle.If the given triangle doesn't cover the lesion area completely then it is further divided into M partitions get the exact shape of skin lesion as shown in Figure 6. The asymmetry of lesion shape is determined using the major and minor axes. Major Axis Length is the length of the line joining centroid of lesion and connecting the two outermost boundary points.

$$
\left(x_{c}, y_{c}\right)=\left(\frac{\sum_{i=1}^{n} x_{i}}{n}, \frac{\sum_{i=1}^{n} y_{i}}{n}\right)
$$

Where,

n: no. of pixels inside the lesion.

$\left(x_{i}, y_{i}\right)$ : coordinates of the $i^{\text {th }}$ pixel of lesion.

The length of the line joining lesion blob centroid and connecting the two closest boundary points is assumed as minor axis length.

Asymmetry feature such as asymmetry index (AI) and lengthening index are used to calculate degree of symmetry. 
Figure 5. Profile of a malignant skin lesion

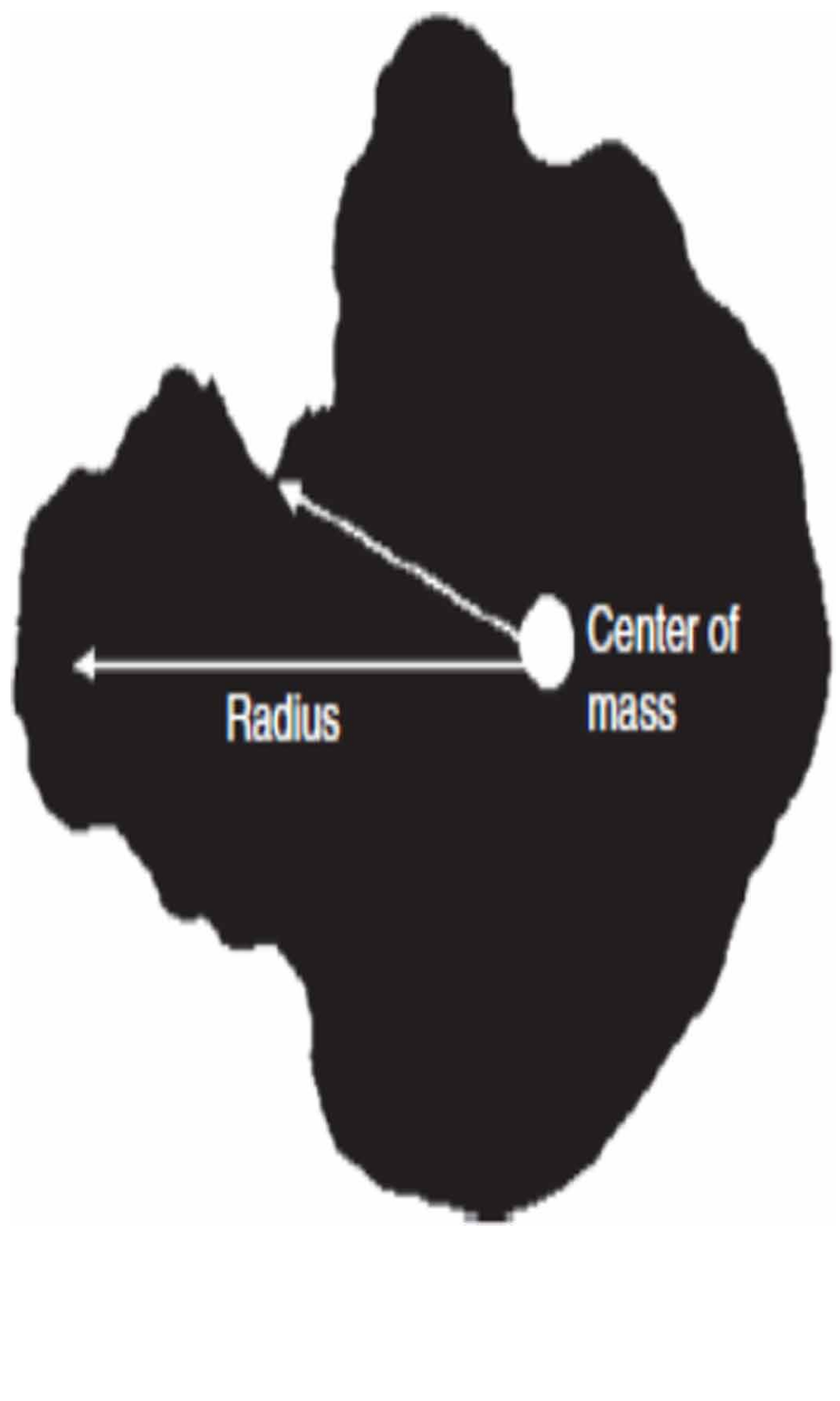

Where,

$\Delta \mathrm{A}$ : Area variance between total image and lesion area.

A: Area of the total Image.

Border irregularity is calculated by shape features such as solidity, compactness, thinness ratio, convexity, circularity index and variance of the distance from the points of the lesion border to the centroid location. Circularity Index (CRC) gives the shape uniformity and is measured by equation:

$$
C R C=\frac{4 \pi A}{P^{2}}
$$

Where, 


\section{Figure 6. Skin lesion detection using Triangulation method}

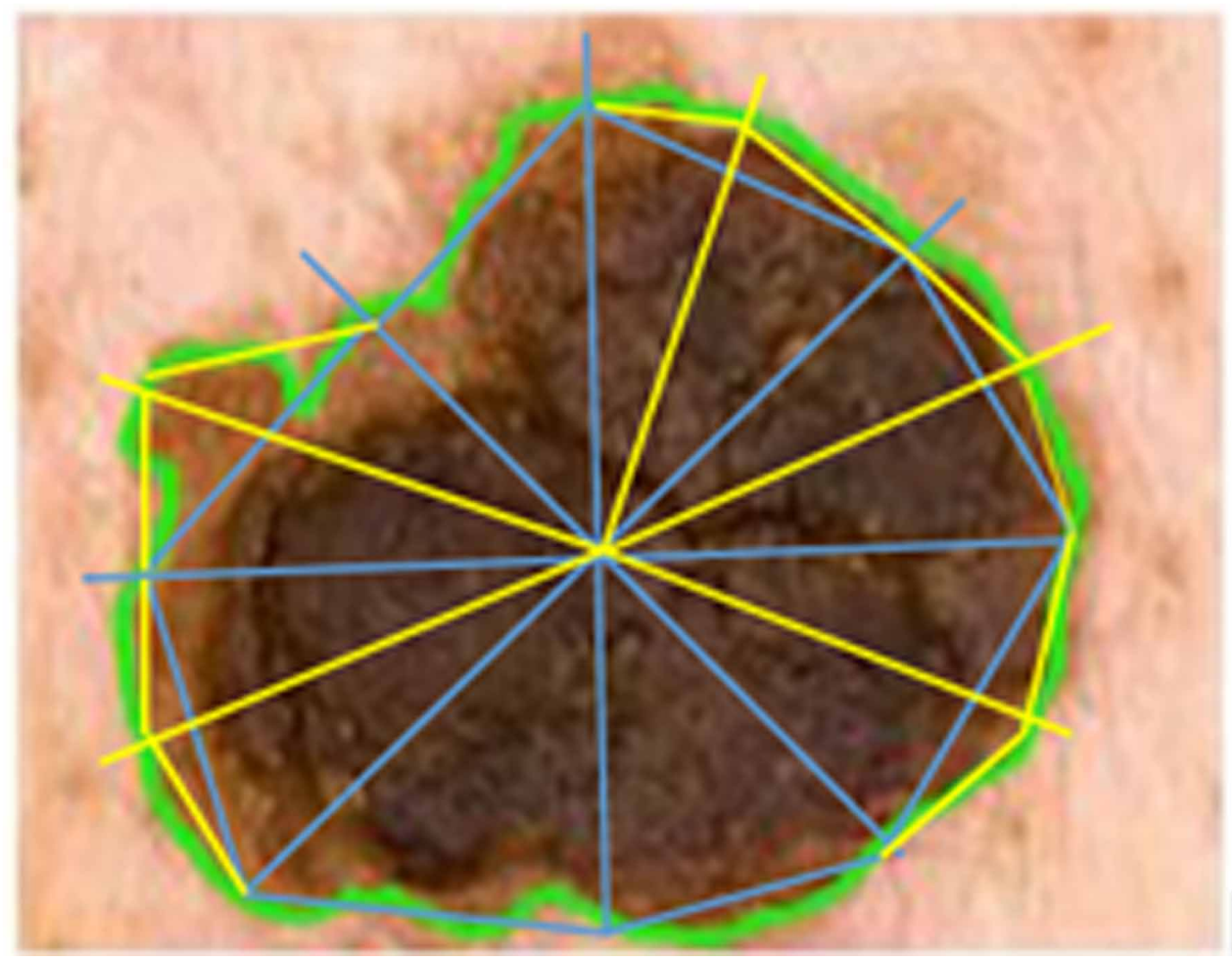

\section{A: Lesion area.}

P: Perimeter of lesion.

Lesion circularity, value ranges from (0 to 1$)$. When the edges are uneven, blurred, and Border Irregularity B value will approaching to zero, which mean irregularly shape. For checking the Roundness (R) of a skin lesion, use R factor; how much the skin lesion look like a circle.

$$
R=\frac{4 \pi \cdot \text { area }_{L}}{\left(\text { perim }_{L}\right)^{2}}
$$

Where,

$$
\begin{aligned}
& \text { permi }_{L}: \text { Perimeter of lesion } \\
& \text { area }_{L} \text { : Area of lesion }
\end{aligned}
$$

Step 5: Now we calculate the diameter (D) of lesion. The average diameter for the lesion can be determined by using the equation: $D=\sqrt{\frac{4 A}{\pi}}$ 
Where $A$ is the lesion's area, the diameter should be less than $6 \mathrm{~mm}$ for benign lesion and more than $6 \mathrm{~mm}$ for malignant.

\section{IMPLEMENTATION OF MOBILE DERMOSCOPY IMAGES ANALYSIS}

Smart phone applications makes life easier for people by capturing skin lesion, if detected early chances of the cure increases significantly.The app checks the asymmetry, border, color, diameter and evolution of lesion and gives us the result of having the melanoma or not. The proposed system App requires only internet connection for sending image and receiving result.The screenshot mobile application is shown in Figure 7.

\section{IMAGE ACQUISITION}

Acquisition of image is the first phase of automatic mobile skin lesion analysis. When image acquired is not acceptably, then the remaining constituents of the system may not be attainable, or the outcome will not be reasonable. For capturing high quality image, phone camera is used along with a dermoscope. Figure 8 . shows images captured using mobile phone camera along with dermoscope attached.

\section{PRE-PROCESSING OF IMAGE}

Input image sent to the system is acquired by using a mobile camera. The image requires to be pre-processed in demand to improve the quality of image (image resizing, contrast and brightness adjustment) and remove the noises. Noises cause classification inaccuracies. We require image preprocessing because of numerous causes: (i) presences of artifacts such as hairs, skin lines, black frames, etc,(ii) irregular borders,(iii) low contrast between surrounding skin and skin lesion. The steps involved in preprocessing are given in Figure 9. Applying different filters such as mean filter, median filter, adaptive wiener filter, adaptive median filter, gaussian filter for de-noising from salt and pepper noise, gaussian noise, speckle noise and poisson noise to get the enhanced image. Morphological operations or Dull razor software are used to remove hair(see Figure 10).

\section{SEGMENTATION OF LESION}

Segmentation of lesion is a second step in which region of interest (ROI) is parted from background as shown in Figure 11. Taking both healthy part as well as lesion part for further processing, result in less accurate classification result. Hence, lesion part is only needed for image segmentation. There are mainly four kind of segmentation technique such as threshold base, region based, pixel based and model based technique.

Otsu thresholding method is used to perform lesion segmentation, which will convert image into binary image. Morphological filter is applied to smooth the edges as edges of the output image become irregular after otsu thresholding method. Automatic thresholding and masking operation in $\mathrm{R}, \mathrm{G}$ and $\mathrm{B}$ planes is used to achieve lesion segmentation. Otsu automatic thresholding is first applied in each plane, then each plan's binary mask is obtained which are then used to obtain final lesion mask by combined them. 3-plane masking procedure is used to increase accuracy of segmentation. Further segmentation, edge detection is applied.

\section{SKIN LESION FEARURE EXTRACTION}


Figure 7. Screenshot mobile application

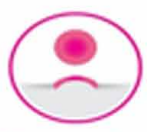

Skin Lesion

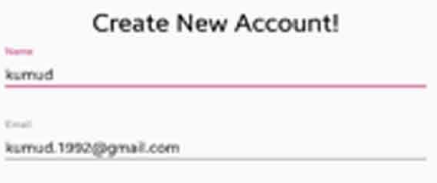

$+$

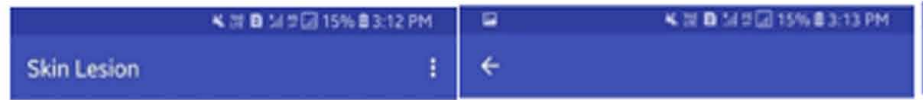

Health Card

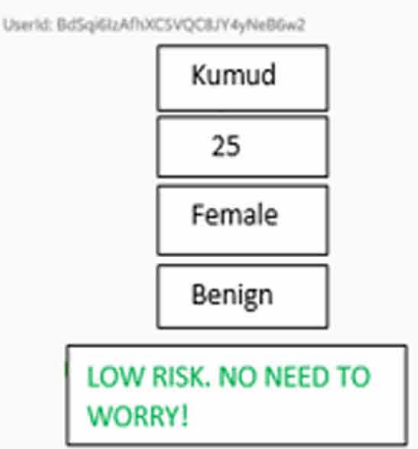

Upload Image

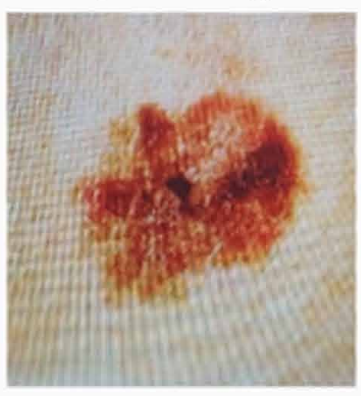

\begin{tabular}{|c|}
\hline Kumud \\
\hline 25 \\
\hline
\end{tabular}

Benign VORRY!
Log in to your Account

bunual 1909 gejesticon

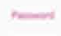

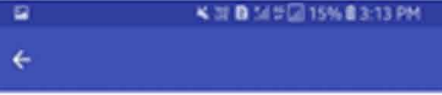

Health Card

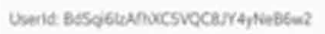

\begin{tabular}{|c|}
\hline Kumud \\
\hline 25 \\
\hline Female \\
\hline \hline Malignant \\
\hline
\end{tabular}

HIGH RISK. CONSULT A DOCTOR. 
Figure 8. Modern digital dermoscope image

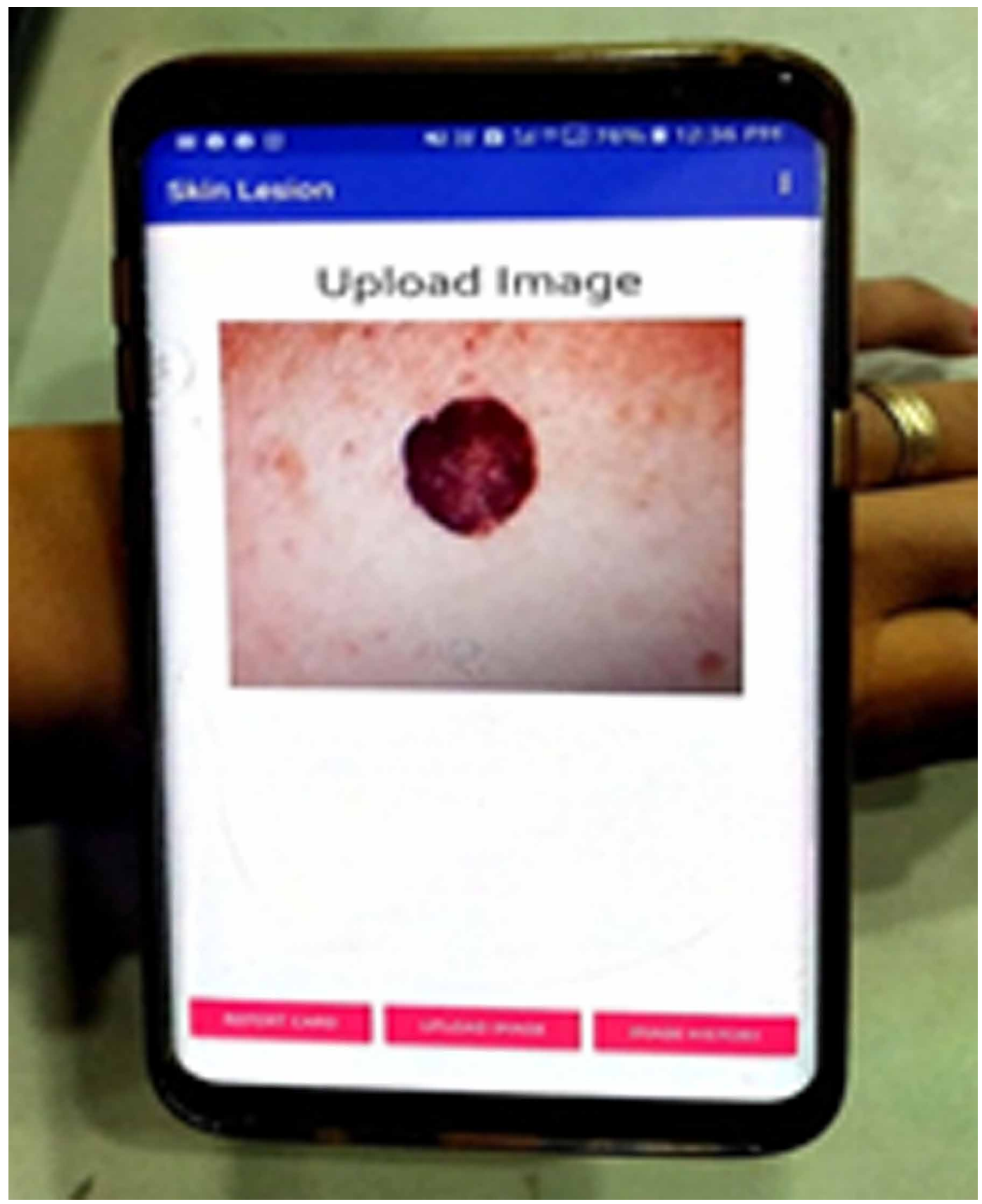

Figure 9. Preprocessing steps

\begin{tabular}{|c|} 
Ac quisition of \\
image as input
\end{tabular}$\rightarrow \begin{gathered}\text { Obtaining the } \\
\text { grayscale } \\
\text { image }\end{gathered} \rightarrow$ Noise filtering $\rightarrow$\begin{tabular}{c|} 
Binary image \\
generation
\end{tabular}



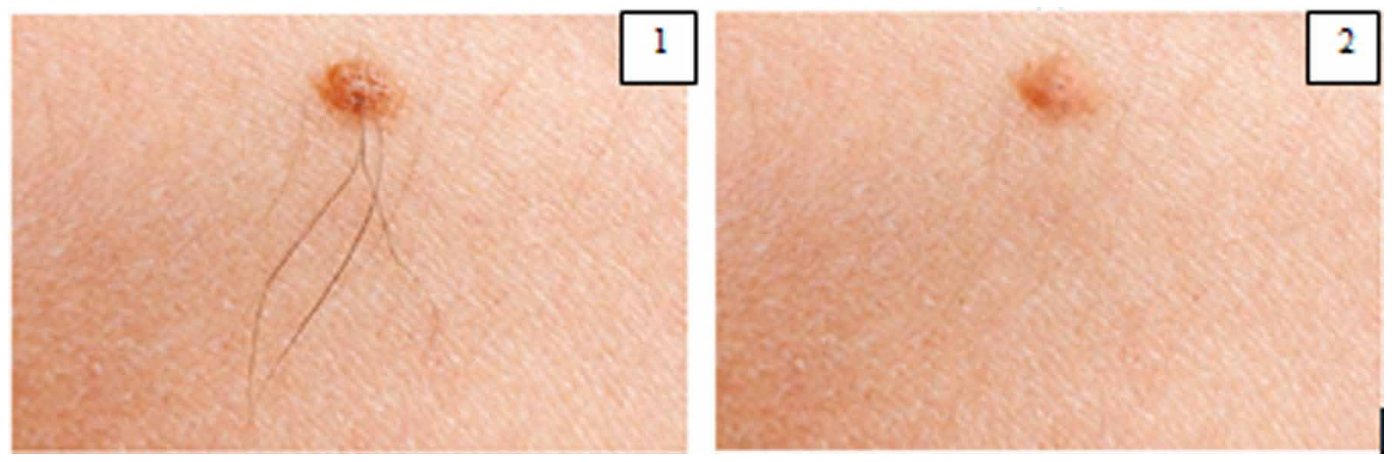

Figure 11. Segmenting skin lesion: (1) Real image, (2) Mask image, (3) detection of biggest blob in input image and (4)Edge detection of skin lesion.
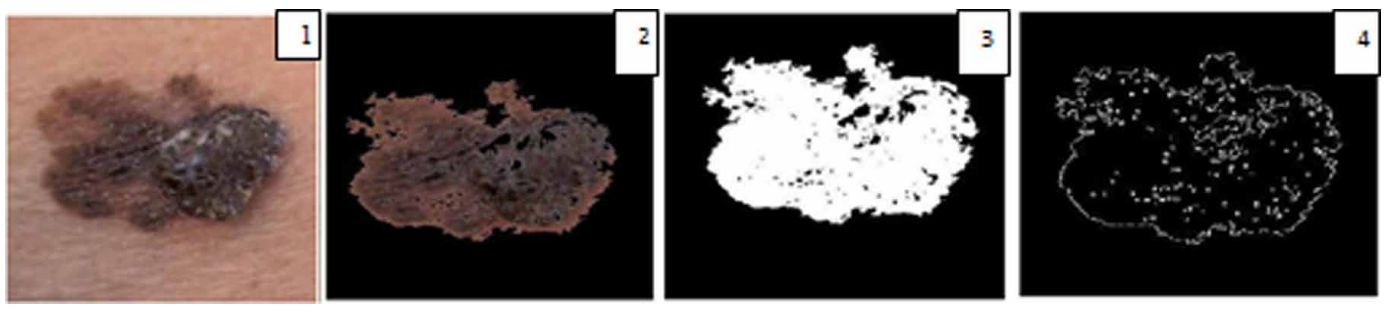

It is challenging to differentiate malignant melanoma from benign melanoma as they are visible same as in the early stages. Some distinctive features such as irregular streaks, multiple brown dots, blue white veil and multiple color are used to differentiate malignant melanoma from benign melanoma. Border, texture and color related features are extracted, after skin lesion area is calculated. Different features extraction techniques (see Figure 12) are as follows:

1. Color feature Extraction: Skin lesion have a variety of colors which include tan, blue,dark brown, red, black and light gray. Melanoma is typically regarded by three or more colors and even five or six colors are present in about $40 \%$ of melanomas. We analyze the color variation through four different channels including green, red, blue and intensity. Intensity channel for each pixel $(x, y)$ is defined as:

$$
I(x, y)=\sqrt{R^{2}(x, y)+G^{2}(x, y)+B^{2}(x, y)}
$$

To compute the color data present in a skin lesion, 4 indicators will be retrieved: mean, variation, standard deviation and skewness. These attributes will be extracted from segmented lesion area over individual channels of the six altered color spaces. Color differs consistently from the center to the edges for normal skin lesion. Lesion is distributed into M number of parts and then it is distributed into $\mathrm{N}$ subparts. Then every part will be labelled by a $\mathrm{N}$-component (every constituent is the average of pixel values of a subpart) vector. In the last stage, color variation measures maximum distance between the vectors. Method is used for red,green,blue and intensity channel of lesion. 4; 8; 12 and 16 are the values of M; 2; 4 and 8 are the value of N. An image for proposed technique is shown in Figure 13. 
Figure 12. Different feature extraction techniques

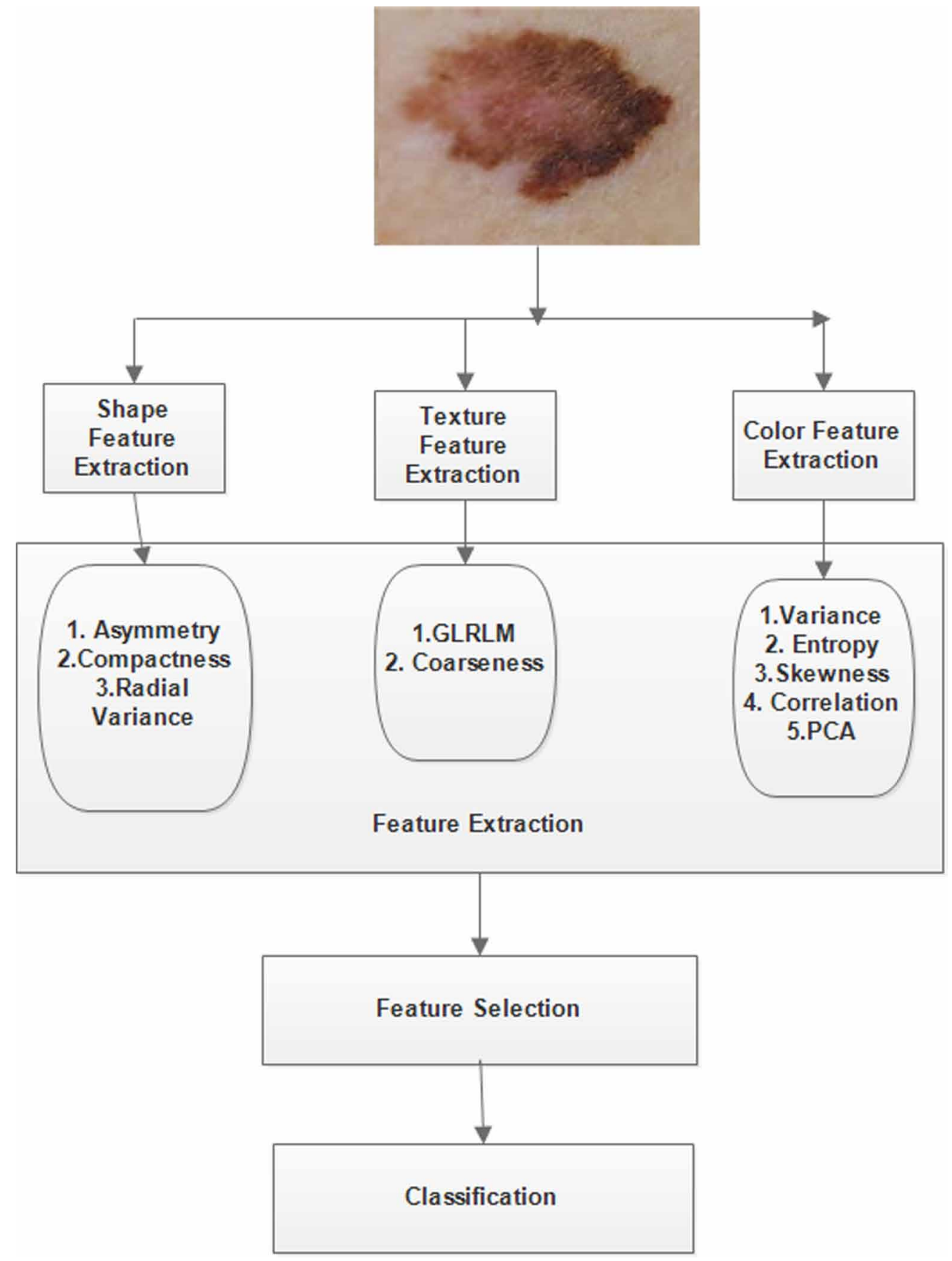


Figure 13. Color triangle

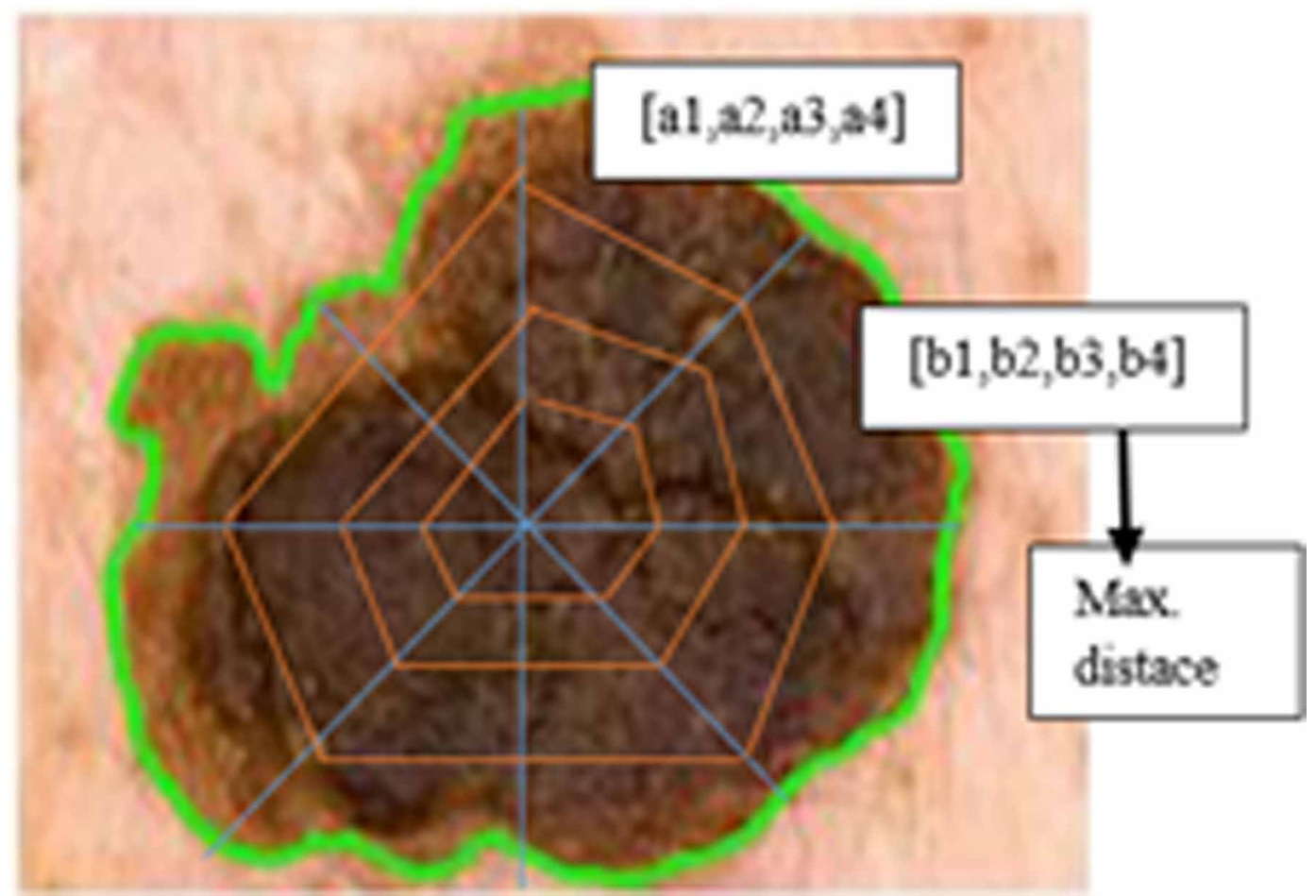

a. $\mu$ : Mean is the average of intensity pixels belonging to lesion.

$\mu=\frac{1}{N} \sum_{j=1}^{N} p$

b. $\sigma^{2}$ : Variance is the variation of the color distribution.

$$
\sigma^{2}=\frac{1}{N} \sum_{j=1}^{N}\left(p_{j}-\mu\right)^{2}
$$

c. $\sigma:$ Standard divation is the square root of the variance of the distribution.

$$
\sigma=\sqrt{\frac{1}{N} \sum_{j=1}^{N}\left(p_{j}-\mu\right)^{2}}
$$

d. S: Skewness is the measure of the degree of asymmetry in the distribution. 
$S=\sqrt[3]{\frac{1}{N}\left(\sum_{j=1}^{N}\left(p_{j}-\mu\right)^{3}\right)}$

2. Texture Features Extraction: Texture signify tonal dissimilarities in the spatial domain and defines general pictorial coarseness or smoothness in image. Spectral, structural and statistical are three main classes of texture processing algorithm. Statistical texture feature is used in classifying malignant and benign tissues. Gray Level Co-occurrence Matrix $\left(\mathrm{GLCM} \rightarrow C_{i, j}\right.$. is a formulation; how frequently diverse combinations of pixel intensity values take place in an image.

a. Entropy calculates the irregularity of distribution of grey level.

$\sum_{i} \sum_{j} C_{i, j} \log \left(C_{i, j}\right)$

b. Energy determines the sum of squared elements in GLCM.

$\sum_{i} \sum_{j} C_{i, j}^{2}$

c. Contrast calculates the local variation in GLCM.

$\sum_{i} \sum_{j}(i-j)^{2} C_{i, j}$

d. Correlation calculates the joint probability of quantified pixel points occurrence.

$\sum_{i, j=0}^{k-1} C_{i, j}\left[\frac{(i-1 / 4)(j-1 / 4)}{1 / \tilde{A}_{1}^{2} \tilde{A}_{j}^{2}}\right]$

e. Homogeneity determines nearness of element's distribution in GLCM.

$\sum_{i} \sum_{j} \frac{C_{i, j}}{1+|i-j|}$

\section{CLASSIFICATION}

Final step of mobile dermoscopy images analysis is a classification of lesion and it determines whether the given lesion is benign or malignant. Various classifiers such as K-nearest neighbourhood, discriminant analysis, decision trees, artificial neural network and support vector machine are used for classification purpose. Convolutional neural networks $(\mathrm{CNN})$ is used as classifier and they find specific patterns that can be local (with irregular streaks, pigment network, inadequate pigmentation, 
blue-white veil, globules or black dots, vascular structures, regression structures) or global (with globular, reticular, homogenous, cobblestone, parallel multi component, starburst, unspecific).

\section{RESULTS}

Dataset of 350 dermoscopic images are used to calculate the performance of proposed technique. Dataset is a collection of $\mathrm{PH}^{2}$ database, collected from the Hospital of Pendre Hispano, Matosinhos, Portugal and other different medical sites like http://www.dermoscopic.blogspot.com or http://www2. fc.up.pt/addi. Total number of common nevi image is 130, Atypical nevi image is 120, and Melanoma images is 100 . Proposed model is based upon lesion segmentation and classification of lesion. Seven different classes of skin diseases were selected like: melanoma, melanocytic nevi, benign keratosis, dermatofibroma, vascular skin lesion, basal cell carcinoma, seborrheic keratosis. Some samples of seven different classes of skin lesion are shown in Table 3.

The Color feature and Texture feature sets are being used for its (Convolution Neural Network's) training and testing. The performance measures of CNN like Accuracy, Sensitivity and Specificity were examined to check the performance of all these different feature sets.

1. Accuracy $=\frac{\text { Number of classified mass }}{\text { Number of total mass }}=\frac{T P+T N}{T P+T N+F P+F N}=81.33 \%$

2. Sensitivity $=\frac{\text { Number of correct classified malignant mass }}{\text { Number of total malignant masses }}=\frac{T P}{T P+F N}=78.66 \%$

3. Specificity $=\frac{\text { Number of correct classified benign }}{\text { Number of total benign masses }}=\frac{T N}{T N+F P}=84 \%$

In the above calculation method the abbreviation of the same is as follow: TN stands for true negative, FN is false negative, TP is True positive and FP is false positive. Performance of a classifier may be calculated on behalf of the number of false positives and True positives.

\section{CONCLUSION}

The technique proposed has limitless possibilities with accuracy at par with existing algorithms. Technique proposed has been implemented with the help of app, an alternative to the naked-eye analysis performed by a dermatologist. Efficieny of the algorithm will improve as the number of samples and hence training set increase. Accuracy of proposed technique can be further improved with normalization of the intensities and inclusion of more robhust features. To improve accuracy and have consistent results while performing lesion detection, it is recommended that comparison of segmentation algorithms should be done on the same set of lesion images. Number of the classification models proposed in the literature still exhibit some challenges such as unbalance between lesion image classes, the difficulty in defining discriminating visual features and the effect of multiplicities of some lesion image classes. We believe that a good classification model requires less number of features to discriminate between lesion categories. In most of the articles and literature it has been assume that malignant moles are pigmented. However, many journals reported the increment of nonpigmented skin tumours as well as clinically and dermoscopic featureless moles being misdiagnosed during both clinical examination and dermoscopy screening, to which a careful approach is required.

Sunlight forms the source nutrients and vitamins in large number of beings and is the crux for many synthesis operations, however ultraviolet radiation from sunlight is categorized as a "fully carcinogen" since it is both a mutagen and a non-specific damaging catalyst and has characteristics of both a tumor initiator and a tumor promoter. In India, skin cancer constitutes a small but significant proportion of patients with approximately $1-2 \%$ of all diagnosed cancer. In order to reduce the mortality rate due to 
Table 3. Few samples of seven different classes of skin lesion

\begin{tabular}{|c|c|}
\hline Images & Results \\
\hline & $\begin{array}{l}\text { 1. nv, Melanocytic Nevi: } 0.622804 \\
\text { 2. bkl, Benign Keratosis: } 0.248136 \\
\text { 3. df, Dermatofibroma: } 0.078298 \\
\text { 4. vasc, Vascular skin lesion: } 0.050061 \\
\text { 5. mel, Melanoma: } 0.000400 \\
\text { 6. akiec, Actinic Keratoses (Solar Keratoses) or intraepithelial Carcinoma } \\
\text { (Bowen's disease): } 0.000188 \\
\text { 7. bcc, Basal Cell Carcinoma: } 0.000113\end{array}$ \\
\hline & $\begin{array}{l}\text { 1. nv, Melanocytic Nevi: } 0.972513 \\
\text { 2. mel, Melanoma: } 0.024583 \\
\text { 3. df, Dermatofibroma: } 0.002865 \\
\text { 4. bkl, Benign Keratosis: } 0.000038 \\
\text { 5. akiec, Actinic Keratoses (Solar Keratoses) or intraepithelial Carcinoma } \\
\text { (Bowen's disease): } 0.000001 \\
\text { 6. bcc, Basal Cell Carcinoma: } 0.000000 \\
\text { 7. vasc, Vascular skin lesion: } 0.000000\end{array}$ \\
\hline & $\begin{array}{l}\text { 1. bkl, Benign Keratosis: } 0.902541 \\
\text { 2. vasc, Vascular skin lesion: } 0.037958 \\
\text { 3. nv, Melanocytic Nevi: } 0.032072 \\
\text { 4. df, Dermatofibroma: } 0.022653 \\
\text { 5. mel, Melanoma: } 0.003709 \\
\text { 6. bcc, Basal Cell Carcinoma: } 0.000965 \\
\text { 7. akiec, Actinic Keratoses (Solar Keratoses) or intraepithelial Carcinoma } \\
\text { (Bowen's disease): } 0.000103\end{array}$ \\
\hline & $\begin{array}{l}\text { 1. mel, Melanoma: } 0.507914 \\
\text { 2. bkl, Benign Keratosis: } 0.343390 \\
\text { 3. df, Dermatofibroma: } 0.099514 \\
\text { 4. nv, Melanocytic Nevi: } 0.029063 \\
\text { 5. akiec, Actinic Keratoses (Solar Keratoses) or intraepithelial Carcinoma } \\
\text { (Bowen's disease): } 0.017317 \\
\text { 6. vasc, Vascular skin lesion: } 0.001863 \\
\text { 7. bcc, Basal Cell Carcinoma: } 0.00093\end{array}$ \\
\hline & $\begin{array}{l}\text { 1. bkl, Benign Keratosis: } 0.999228 \\
\text { 2. akiec, Actinic Keratoses (Solar Keratoses) or intraepithelial Carcinoma } \\
\text { (Bowen's disease): } 0.000722 \\
\text { 3. vasc, Vascular skin lesion: } 0.000049 \\
\text { 4. mel, Melanoma: } 0.000001 \\
\text { 5. nv, Melanocytic Nevi: } 0.000000 \\
\text { 6. bcc, Basal Cell Carcinoma: } 0.000000 \\
\text { 7. df, Dermatofibroma: } 0.000000\end{array}$ \\
\hline & $\begin{array}{l}\text { 1. bkl, Benign Keratosis: } 0.988609 \\
\text { 2. nv, Melanocytic Nevi: } 0.010655 \\
\text { 3. mel, Melanoma: } 0.000298 \\
\text { 4. df, Dermatofibroma: } 0.000205 \\
\text { 5. akiec, Actinic Keratoses (Solar Keratoses) or intraepithelial Carcinoma } \\
\text { (Bowen's disease): } 0.000097 \\
\text { 6. vasc, Vascular skin lesion: } 0.000079 \\
\text { 7. bcc, Basal Cell Carcinoma: } 0.000056\end{array}$ \\
\hline$t$ & $\begin{array}{l}\text { 1. df, Dermatofibroma: } 0.998953 \\
\text { 2. nv, Melanocytic Nevi: } 0.000583 \\
\text { 3. mel, Melanoma: } 0.000406 \\
\text { 4. bkl, Benign Keratosis: } 0.000046 \\
\text { 5. bcc, Basal Cell Carcinoma: } 0.000010 \\
\text { 6. vasc, Vascular skin lesion: } 0.000001 \\
\text { 7. akiec, Actinic Keratoses (Solar Keratoses) or intraepithelial Carcinoma } \\
\text { (Bowen's disease): } 0.000001\end{array}$ \\
\hline
\end{tabular}


Table 3. Continued

\begin{tabular}{|l|l|}
\hline Images & Results \\
\hline & 1. bkl, Benign Keratosis: 0.946399 \\
& 2. nv, Melanocytic Nevi: 0.034633 \\
& 3. mel, Melanoma: 0.017547 \\
& 4. akiec, Actinic Keratoses (Solar Keratoses) or intraepithelial Carcinoma \\
& (Bowen's disease): 0.001319 \\
& 5. vasc, Vascular skin lesion: 0.000055 \\
& 6. df, Dermatofibroma: 0.000039 \\
& 7. bcc, Basal Cell Carcinoma: 0.000006 \\
\hline & 1. mel, Melanoma: 0.994695 \\
& 2. nv, Melanocytic Nevi: 0.004144 \\
& 3. bkl, Benign Keratosis: 0.001128 \\
& 4. akiec, Actinic Keratoses (Solar Keratoses) or intraepithelial Carcinoma \\
& (Bowen's disease): 0.000024 \\
& 5. df, Dermatofibroma: 0.000008 \\
& 6. bcc, Basal Cell Carcinoma: 0.000000 \\
& 7. vasc, Vascular skin lesion: 0.000000 \\
& \\
\hline & \\
\hline
\end{tabular}

Table 4. Confusion matrix

\begin{tabular}{|l|l|l|}
\hline \multicolumn{1}{|c|}{ True/Predicted } & \multicolumn{1}{c|}{ Malignant } & \multicolumn{1}{c|}{ Benign } \\
\hline Malignant & 59 & 16 \\
\hline Benign & 12 & 63 \\
\hline
\end{tabular}

skin cancer early diagnosis can play a vital role. This article presents a real time mobile phone-aided melanoma skin lesion detection using triangulation technique, it has capabilities to segment skin lesions in dermoscopy images using triangulation method for faster segemetation; categorization as different type and levels of infection is achieved through convolution neural network (CNN). Captured image techniques will make non-invasive skincancer detection and does not require laboratory testing which makes this system less time consuming and inexpensive. Performance achieved is at par with existing algorithms with improved time consumption. Accuracy, sensitivity and specificity achieved was $81.33 \%, 78.66 \%$, and $84 \%$, respectively. 


\section{REFERENCES}

Argenziano, G., Catricala, C., Ardigo, M., Buccini, P., De Simone, P., Eibenschutz, L., \& Zalaudek, I. et al. (2011). Seven-point checklist of dermoscopy revisited. British Journal of Dermatology, 164(4), 785-790. doi:10.1111/j.1365-2133.2010.10194.x PMID:21175563

Argenziano, G., \& Soyer, H. P. (2001). Dermoscopy of pigmented skin lesions-a valuable tool for early. The Lancet Oncology, 2(7), 443-449. doi:10.1016/S1470-2045(00)00422-8 PMID:11905739

Argenziano, G., Soyer, H. P., Chimenti, S., Talamini, R., Corona, R., Sera, F., \& Hofmann-Wellenhof, R. et al. (2003). Dermoscopy of pigmented skin lesions: Results of a consensus meeting via the Internet. Journal of the American Academy of Dermatology, 48(5), 679-693. doi:10.1067/mjd.2003.281 PMID:12734496

Bafounta, M. L., Beauchet, A., Aegerter, P., \& Saiag, P. (2001). Is dermoscopy (epiluminescence microscopy) useful for the diagnosis of melanoma?: Results of a meta-analysis using techniques adapted to the evaluation of diagnostic tests. Archives of Dermatology, 137(10), 1343-1350. doi:10.1001/archderm.137.10.1343 PMID:11594860

Celebi, M. E., Iyatomi, H., Schaefer, G., \& Stoeck, W. V. (2009). Lesion border detection in dermoscopy images. Computerized Medical Imaging and Graphics, 33(2), 148-153. doi:10.1016/j.compmedimag.2008.11.002 PMID:19121917

Celebi, M. E., Kingravi, H. A., Uddin, B., Iyatomi, H., Aslandogan, Y. A., Stoecker, W. V., \& Moss, R. H. (2007). A methodological approach to the classification of dermoscopy images. Computerized Medical Imaging and Graphics, 31(6), 362-373. doi:10.1016/j.compmedimag.2007.01.003 PMID:17387001

Doukas, C., Stagkopoulos, P., Kiranoudis, C. T., \& Maglogiannis, I. (2012). Automated skin lesion assessment using mobile technologies and cloud platforms. Proceedings of the 2012 Annual International Conference of the IEEE Engineering in Medicine and Biology Society (EMBC) (pp. 2444-2447). IEEE Press. doi:10.1109/ EMBC.2012.6346458

Gachon, J., Beaulieu, P., Sei, J. F., Gouvernet, J., Claudel, J. P., Lemaitre, M., \& Grob, J. J. et al. (2005). First prospective study of the recognition process of melanoma in dermatological practice. Archives of Dermatology, 141(4), 434-438. doi:10.1001/archderm.141.4.434 PMID:15837860

Garnavi, R., Aldeen, M., \& Bailey, J. (2012). Computer-aided diagnosis of melanoma using border-and waveletbased texture analysis. IEEE Transactions on Information Technology in Biomedicine, 16(6), 1239-1252. doi:10.1109/TITB.2012.2212282 PMID:22893445

Garnavi, R., Aldeen, M., Celebi, M. E., Bhuiyan, A., Dolianitis, C., \& Varigos, G. (2010). Automatic segmentation of dermoscopy images using histogram thresholding on optimal color channels. International Journal of Medicine and Medical Sciences, 1(2), 126-134.

Henning, J. S., Dusza, S. W., Wang, S. Q., Marghoo, A. A., Rabinovitz, H. S., Polsky, D., \& Kopf, A.W. (2007). The CASH (color, architecture, symmetry, and homogeneity) algorithm for dermoscopy. Journal of the American Academy of Dermatology, 56(1), 45-52. doi:10.1016/j.jaad.2006.09.003 PMID:17190620

Iyatomi, H., Oka, H., Saito, M., Miyake, A., Kimoto, M., Yamagami, J., \& Argenziano, G. et al. (2006). Quantitative assessment of tumour extraction from dermoscopy images and evaluation of computer-based extraction methods for an automatic melanoma diagnostic system. Melanoma Research, 16(2), 183-190. doi:10.1097/01.cmr.0000215041.76553.58 PMID:16567974

Karargyris, A., Karargyris, O., \& Pantelopoulos, A. (2012). DERMA/care: An advanced image-processing mobile application for monitoring skin cancer. Proceedings of the 2012 IEEE 24th International Conference on Tools with Artificial Intelligence. IEEE Press.

Kawahara, J., BenTaieb, A., \& Hamarneh, G. (2016). Deep features to classify skin lesions,IEEE. Proceedings of the 2016 IEEE 13th International Symposium on Biomedical Imaging (ISBI) (pp. 1397-1400). IEEE Press.

Kittler, H., Pehamberger, H., Wolff, K., \& Binder, M. (2002). Diagnostic accuracy of dermoscopy. The Lancet Oncology, 3(3), 159-165. doi:10.1016/S1470-2045(02)00679-4 PMID:11902502

Korotkov, K., \& Garcia, R. (2012). Computerized analysis of pigmented skin lesions: A review. Artificial Intelligence in Medicine, 56(2), 69-90. doi:10.1016/j.artmed.2012.08.002 PMID:23063256 
Liu, Z., Sun, J., Smith, L., Smith, M., \& Warr, R. (2012). Distribution quantification on dermoscopy images for computer-assisted diagnosis of cutaneous melanomas. Medical \& Biological Engineering \& Computing, 50(5), 503-513. doi:10.1007/s11517-012-0895-7 PMID:22438064

Maglogiannis, I., \& Doukas, C. N. (2009). Overview of advanced computer vision systems for skin lesions characterization. IEEE Transactions on Information Technology in Biomedicine, 13(5), 721-733. doi:10.1109/ TITB.2009.2017529 PMID:19304487

Massone, C., Brunasso, A. M., Campbell, T. M., \& Soyer, H. P. (2009). Mobile teledermoscopy--melanoma diagnosis by one click? Seminars in Cutaneous Medicine and Surgery, 28(3), 203-205. doi:10.1016/j. sder.2009.06.002 PMID:19782945

Menzies, S. W. (2001). A method for the diagnosis of primary cutaneous melanoma using surface microscopy. Dermatologic Clinics, 19(2), 299-305. doi:10.1016/S0733-8635(05)70267-9 PMID:11556238

Nachbar, F., Stolz, W., Merkle, T., Cognetta, A. B., Vogt, T., Landthaler, M., \& Plewig, G. et al. (1994). The ABCD rule of dermatoscopy: High prospective value in the diagnosis of doubtful melanocytic skin lesions. Journal of the American Academy of Dermatology, 30(4), 551-559. doi:10.1016/S0190-9622(94)70061-3 PMID:8157780

Ng, V. T., Fung, B. Y., \& Lee, T. K. (2005). Determining the asymmetry of skin lesion with fuzzy borders. Computers in Biology and Medicine, 35(2), 103-120. doi:10.1016/j.compbiomed.2003.11.004 PMID:15567181

Ramlakhan, K., \& Shang, Y. (2011). A mobile automated skin lesion classification system. Proceedings of the 2011 IEEE 23rd International Conference on Tools with Artificial Intelligence (pp. 138-141). IEEE Press. doi:10.1109/ICTAI.2011.29

Razmjooy, N., Mousavi, B. S., Soleymani, F., \& Khotbesara, M. H. (2013). A computer-aided diagnosis system for malignant melanomas. Neural Computing \& Applications, 23(7-8), 2059-2071. doi:10.1007/s00521-012-1149-1

Satheesha, T. Y., Narayana, D. S., \& Giriprasad, M. N. (2012). Review on early detection of melanoma in situ. International Journal of Advanced Technology \& Engineering Research, 2(4), 80-90.

Sheha, M. A., Mabrouk, M. S., \& Sharawy, A. (2012). Automatic detection of melanoma skin cancer using texture analysis. International Journal of Computers and Applications, 42(20), 22-26. doi:10.5120/5817-8129

Soyer, H. P., Argenziano, G., Zalaudek, I., Corona, R., Sera, F., Talamini, R., \& Farro, P. et al. (2004). Threepoint checklist of dermoscopy. Dermatology, 208(1), 27-31. doi:10.1159/000075042 PMID:14730233

Stolz, W. (1994). ABCD rule of dermatoscopy: A new practical method for early recognition of malignant melanoma. European Journal of Dermatology, 4, 521-527.

Sumithra, R., Suhil, M., \& Guru, D. S. (2015). Segmentation and classification of skin lesions for disease diagnosis. Procedia Computer Science, 45, 76-85. doi:10.1016/j.procs.2015.03.090

Wadhawan, T., Situ, N., Lancaster, K., Yuan, X., \& Zouridakis, G. (2011). SkinScan: a portable library for melanoma detection on handheld devices. Proceedings of the 2011 IEEE International Symposium on Biomedical Imaging: From Nano to Macro (pp. 133-136). IEEE Press. 
Kumud Tiwari is currently pursuing her Ph.D. degree in Electronics and Communication Engineering at Amity University, Lucknow Campus, Uttar Pradesh, India. She obtained her Master's degree in Electronics and Communication Engineering from Babu Banarasi Das University, Lucknow, Uttar Pradesh (2016) and received her Bachelor's degree in Electronics and Communication Engineering from Lovely Professional University, Phagwara, Punjab (2014). Her research interests include Healthcare industry, Machine Learning, Artificial Intelligence, Cloud Computing, Fog Computing, Internet of Things and Wireless Sensor Networks. She is a member of the IEEE Communications Society. She has published a number of research papers in various reputed Journals indexed in SCOPUS and presented a number of papers in various reputed National and International Conferences.

Sachin Kumar is a Ph.D. in Electronics from Dr R M L Univesity, M. Tech. and B.E in Electronics \& Communication from Pune University, Presently he is working as Assistant Professor in Department of Electronics \& Communication, Amity University, Lucknow Campus. His research areas include applications of Digital Image Processing, BioMedical Signal Processing, Machine Learning \& Applications of Wireless Sensor Networks. He is an active member of the following international professional bodies IEEE, IETE, IAENG, ISC and IET(UK), he has published large number of research papers in various reputed Journals indexed in SCOPUS \& ESCI and Presented large number of papers in various reputed National and International Conferences and has also been part of Organizing committee in National/International Workshop/Conferences, further he is an active member of Editorial Board/Reviewer in various journals, indexed in Scopus, SCl and ESCl.

R.K. Tiwari is working as a Professor in Department of Physics and Electronics, Dr. RML Avadh University, Faizabad, He is also the Dean Faculty of Science.Previously he has also worked as Director, IET, Dr. RML Avadh University, Faizabad and Dean Student Welfare at the Dr. RML Avadh University, Faizabad. He has published research articles in numerous international journals and international conferences. He has also been the member of the executive council and a member of various academic bodies. 